\title{
Ileal ulcers in a long-distance runner diagnosed by capsule endoscopy
}

\author{
J. Valle, J. Morillas ${ }^{1}$, M. J. Pérez-Grueso, J. M. Carrobles and J. L. Martínez-Potenciano \\ Hospital Virgen de la Salud. Toledo. 'Hospital Virgen de la Luz. Cuenca. Spain
}

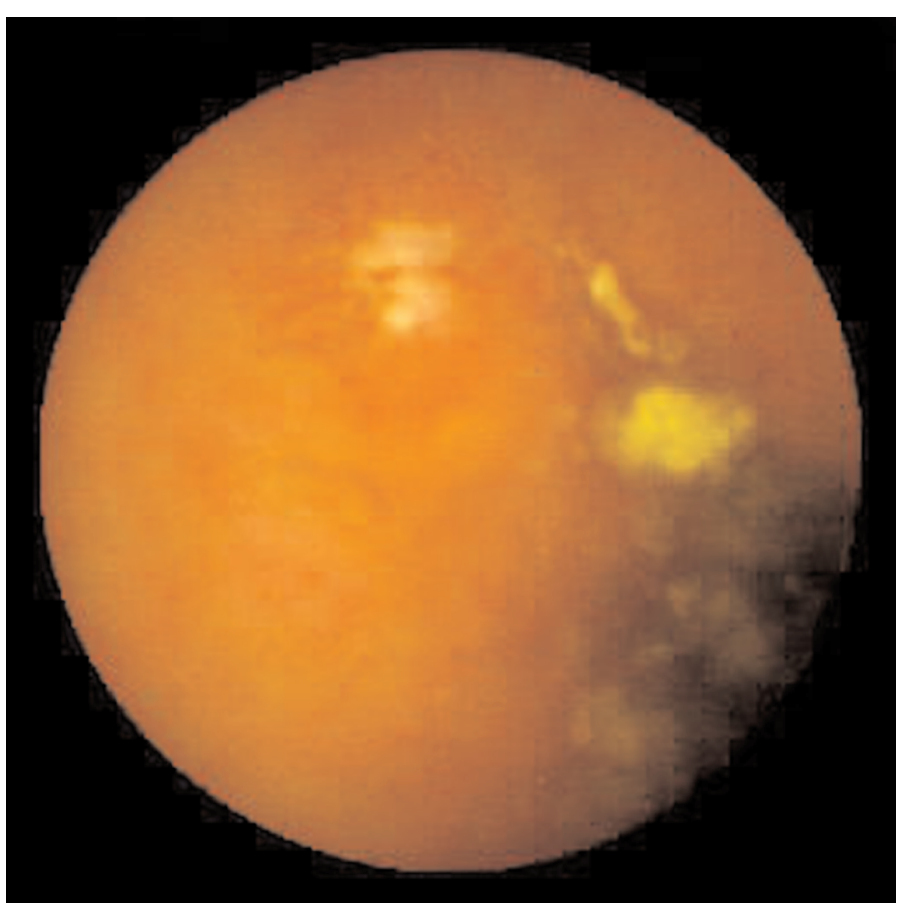

Fig. 1.

A 31-year-old man committed to run twenty kilometres daily was admitted into the hospital two years ago because of severe microcytic anemia $(\mathrm{Hb}: 9.2 \mathrm{~g} / \mathrm{dL}$, MCV: $71 \mathrm{fl})$. He was not taking anti-inflammatory drugs, or any other medication. Upper gastrointestinal endoscopy, ileocolonoscopy and small bowel barium follow-through were all normal. The patient was discharged on oral iron supplements with a diagnosis of chronic iron deficiency anemia of unknown origin. Two months ago, the patient was admitted again because of melena for three days. He had no other gastrointestinal symptoms. Blood tests showed a mild normocytic anemia (Hb: 11.1 $\mathrm{g} / \mathrm{dL}, \mathrm{MCV}$ : $87.1 \mathrm{fl}$ ). An upper gastrointestinal endoscopy showed a short-segment Barrett's esophagus without evidence of erosive esophagitis. A small-bowel follow-through was normal, and antiendomysial antibodies were negative. Capsule endoscopy showed two adjacent ulcers located in the proximal ileum (Fig. 1). After this diagnosis, the patient was advised to stop training. Nowadays, he is symptom-free and his hemoglobin level is $14.4 \mathrm{~g} / \mathrm{dL}$.

Up to $20 \%$ of long-distance runners develop hemoccult-positive stools after a marathon, and there have been reported cases of overt gastrointestinal bleeding. Decreased gastrointestinal blood flow has been postulated as the main mechanism underlying gastrointestinal lesions during strenuous exercise. To our knowledge, this is the first case of running-associated small bowel ulcers diagnosed by capsule endoscopy (1-3).

\section{REFERENCES}

1. Schwartz AE, Vanagunas A, Kamel PL. Endoscopy to evaluate gastrointestinal bleeding in marathon runners. Ann Intern Med 1990; 113: 632-3.

2. Ginard D, Gayá J, Bonét Ll, Sapiña A, Llompart A, Vaquer P, et al. Hemorragia digestiva en un corredor de larga distancia. Rev Esp Enferm Dig 1999; 91: 594-8.

3. Peters HPF, Bos M, Seebregts M, Akkermans LMA, van Berge Henegouwen GP, Bol E, et al. Gastrointestinal symptoms in long-distance runners, cyclist, and triathletes: prevalence, medication, and etiology. Am J Gastroenterol 1999; 94: 1570-81. 


\title{
Úlceras ileales en un corredor de larga distancia diagnosticadas mediante cápsula endoscópica
}

\author{
J. Valle, J. Morillas ${ }^{1}$, M. J. Pérez-Grueso, J. M. Carrobles y J. L. Martínez-Potenciano \\ Hospital Virgen de la Salud. Toledo. 'Hospital Virgen de la Luz. Cuenca
}

Varón de 31 años, corredor de 20 kilómetros al día, que había sido ingresado dos años antes para estudio de una anemia microcítica grave $(\mathrm{Hb} 9,2 \mathrm{~g} / \mathrm{dL}, \mathrm{VCM}: 71 \mathrm{fl})$. El enfermo no estaba tomando fármacos antiinflamatorios ni ninguna otra medicación. Se realizó una endoscopia digestiva alta, una ileocolonoscopia y un tránsito intestinal baritado que fueron normales. El paciente recibió suplementos de hierro por vía oral y fue dado de alta con el diagnóstico de anemia ferropénica de etiología indeterminada. Hace dos meses el paciente ingresó de nuevo por presentar deposiciones melénicas de tres días de duración, sin otra sintomatología acompañante. En la analítica se observó anemia normocítica (Hb: 11,1 gr/dL, VCM: 87,1 fl). En la endoscopia digestiva alta se observó un esófago de Barrett corto sin signos de esofagitis. El tránsito intestinal baritado fue normal y los anticuerpos antiendomisio fueron negativos. En la exploración con cápsula endoscópica se observaron dos úlceras adyacentes situadas en el íleon proximal (Fig. 1). Tras este diagnóstico se aconsejó al paciente que interrumpiera los entrenamientos. Actualmente se encuentra asintomático y su tasa de hemoglobina en sangre es de $14,4 \mathrm{~g} / \mathrm{dL}$.

Hasta un $20 \%$ de los corredores presentan hemorragias ocultas en heces positivas tras un maratón y hay algunos casos descritos de sangrado digestivo visible. Se ha propuesto que el mecanismo por el que se producen las lesiones digestivas en situaciones de esfuerzo extremo es la disminución marcada en el flujo sanguíneo intestinal. Por lo que sabemos, este es el primer caso de úlceras intestinales asociadas a ejercicio intenso que se diagnostica mediante la cápsula endoscópica (1-3). 